\section{MULHERES, POLÍTICAS PÚBLICAS E COMBATE À VIOLẾNCIA dE GÊNERo}

Women, Public Policies and Fight Against Gender Violence
Samira de M. Maia

VIGANO*,**

(D) samirammvigano@gmail.com

Maria Hermínia L. F.

\section{LAFFIN**}

(D) herminialaffin@gmail.com

*Instituto Federal de Educação,
Ciência e Tecnologia de
Santa Catarina
Florianópolis, SC, Brasil
**Universidade Federal de
Santa Catarina,
Florianópolis, SC, Brasil

\section{RESUMO}

Este artigo enfoca políticas de ações afirmativas para as mulheres brasileiras, no seu contexto histórico. O objetivo é demonstrar como tais políticas se constroem, se engendram ou se articulam por meio de direitos assegurados ao longo da história. Trata-se de um texto teórico que aponta trajetórias das ações afirmativas, relações de desigualdade, de violências e como o movimento feminista envolveu-se nessas questões. Os fundamentos utilizados na escrita têm como base os referenciais que abrangem estudos das relações de gênero; movimentos sociais, políticas públicas e inclusão social. O texto divide-se em duas partes: feminismo, gênero e violências; e ações afirmativas de combate à violência contra as mulheres. Ressalta-se que esse debate permite compreender essas violências como violações dos direitos humanos e, por isso, atingem todas as classes sociais.

Palavras-chave: políticas, mulheres, violências, gênero.

\begin{abstract}
This article focuses on affirmative action policies for Brazilian women, in their historical context. The goal is to demonstrate how these policies are built, engendered or articulated through the rights guaranteed throughout history. It is a theoretical text that points out the trajectories of affirmative actions, relations of inequality, violence and how the feminist movement became involved in these issues. The foundations used in this paper are theoretical frameworks that study gender relations; social movements, public policies and social inclusion. Two parts are presented here: feminism, gender and violence; and affirmative action to combat violence against women. It should be emphasized that this debate makes it possible to understand that violence against women is a violation of human rights and therefore affects all social classes.
\end{abstract}

Keywords: policies, women, violence, gender. 
razer ao debate o tema de violência contra as mulheres parece algo que já está ultrapassado, pois vários textos já trataram desse assunto ao longo dos anos, entretanto a violência contra as mulheres está cada dia mais latente e merece destaque nos trabalhos acadêmicos. Sendo assim, o contexto trazido neste artigo busca enfocar algumas políticas públicas de ação afirmativa para as mulheres brasileiras. O objetivo é demonstrar como tais políticas se constroem, engendram ou se articulam por meio de direitos assegurados ao longo da história e alguns reflexos nos processos de proteção às mulheres. A complexidade de trabalhar com um tema deste porte tem como vantagem a ampliação dos debates e o reconhecimento de temáticas invisibilizadas.

Este artigo é proveniente de leituras realizadas no decorrer dos estudos de gênero e sexualidade no curso de Especialização em Gênero e Diversidade na Escola promovida pela Universidade Federal de Santa Catarina (GDE/UFSC), e pelos estudos iniciados no Doutorado em Educação da mesma universidade.

Toma-se por base um conjunto de análises teóricas e dimensões qualitativas que apontam trajetórias das políticas para as mulheres, compreendendo assim, as relações de desigualdade vivenciadas pelas mesmas. Retratar esse tema é representar historicamente como as violências foram culturalmente naturalizadas dentro de um processo histórico de base patriarcal.

Nesse sentido, é importante situar o que se entende por políticas públicas e políticas públicas sociais. Para Höfling (2001) as políticas públicas constituem o "Estado em ação", por meio de programas pensados para setores específicos da sociedade:

As políticas públicas são aqui compreendidas como as de responsabilidade do Estado - quanto à implementação e manutenção a partir de um processo de tomada de decisões que envolve órgãos públicos e diferentes organismos e agentes da sociedade relacionados à política implementada. Neste sentido, políticas públicas não podem ser reduzidas a políticas estatais. (HÖFLING, 2001, p. 31).

A pesquisadora situa que as políticas sociais "se referem a ações que determinam o padrão de proteção social implementado pelo Estado, voltadas, em princípio, para a redistribuição dos benefícios sociais visando à diminuição das desigualdades estruturais produzidas pelo desenvolvimento socioeconômico". (HÖFLING, 2001, p. 31).

Para Azevedo (2004, p. 05), a concepção de políticas públicas “[...] são definidas, implementadas, reformuladas ou desativadas com base na memória da sociedade ou do Estado". Nessa dimensão, constitui-se como fundamental a força dos movimentos e da pressão social na memória da sociedade ou do Estado, com estreita relação às representações sociais que cada sociedade desenvolve sobre si própria na busca da garantia de seus direitos.

Assim, ressalta-se que as políticas públicas sociais são medidas destinadas a atender demandas específicas da população, muitas vezes particularmente grupos discriminados e vitimados por algum mecanismo de exclusão. Tais políticas pretendem 
atuar de forma reparatória nas desigualdades e desvantagens acumuladas durante o percurso histórico de alguns grupos, buscando assegurar ou ampliar o acesso à escolarização, bens materiais e culturais, saúde, trabalho e segurança.

No Brasil, há uma compreensão, quase sempre, equivocada das políticas públicas de ações afirmativas, que acaba por vincular essas ações unicamente à adoção de cotas raciais ou de escola pública para ingresso no ensino superior, adotadas em grande parte das universidades públicas. Entretanto, há ações afirmativas em vários níveis; um deles se relaciona diretamente aos aspectos das violências contra as mulheres.

As ações afirmativas para as mulheres são provenientes do reconhecimento de um sofrimento discriminatório e violento sofrido ao longo dos tempos por esse grupo social, resultando em um tipo especial de violência estruturado na hierarquia de gênero, cunhado nos moldes do patriarcado. Tal contexto fez com que as mulheres fossem reduzidas a uma fragilidade culturalmente apropriada que a fez dependente dos homens e, assim, destinadas a serem violentadas fisicamente e psicologicamente.

As questões de gênero estão vinculadas às expressões do masculino e do feminino, atribuídas historicamente, por meio de imposições sociais e culturais. Essas imposições de caráter biológico, em nossa cultura, estão estritamente ligadas aos papéis que cada um/a tem que assumir socialmente. Acabam sendo injunções sociais e culturais, convenções de naturalização de papéis que designaram poder ao homem e promoveram, como resultado, uma sociedade machista e sexista. Desse modo, a discussão sobre gênero e violência é fundamental para evidenciar os determinismos impostos na sociedade (POGGIO, 2012).

O conceito de gênero enfatiza, assim, a dimensão cultural que apresenta um papel estruturante no processo de tornar-se homem ou mulher. Observa-se, portanto, que ao se falar em gênero, não se fala exclusivamente de macho ou fêmea, mas de masculino e feminino, em diferentes masculinidades e feminilidades. Gênero, assim, remete a construções sociais, históricas, culturais e políticas que dizem respeito a disputas materiais, bem como simbólicas que abrangem processos de configuração de identidades, definições de papéis e funções sociais, des/construções de representações e imagens, distintas distribuições de recursos e de poder entre os que são socialmente definidos como homens e mulheres e o que é - e o que não é - considerado de homem ou de mulher, nas diferentes sociedades e ao longo do tempo. (SANTANA, 2015, p.124).

Para contextualizar essas políticas, dialogando com aspectos sociais e culturais naturalizados em nossa sociedade heterocentrada, adotam-se os seguintes referenciais: Heleith Saffioti (1987; 1999), Guacira Lopes Louro (1995), Mary Del Priore (2013) e Miriam Grossi (1994). Para além dos referenciais mencionados, busca-se dialogar com os dados do Relatório Anual Socioeconômico das Mulheres, organizado pela Secretaria de Políticas para as Mulheres da Presidência da República (SPM/PR), que reúne uma variedade de dados a fim de traçar um diagnóstico sobre as mulheres e suas condições de vida em todas as regiões do Brasil. 
Engloba-se na discussão as particularidades referentes às questões de gênero, sexualidades e cultura. Vale ressaltar que, as estruturas baseadas no patriarcado são contaminadas de relações hierárquicas que dão poder aos homens e submetem as mulheres a situações de subalternidades que se fundamentam em uma suposta inferioridade biológica. Nesse viés, compreender o ser humano em sua constituição cultural e que os preconceitos, discriminações e violências são socialmente aprendidos, revela-se como primeiro passo na desconstrução das normatizações impostas pelos padrões de gênero e de sexualidade.

Afirma-se a necessidade desse debate no atual cenário brasileiro de supostas retiradas de direitos sociais, já que há, uma onda de retrocessos que incidem diretamente nas conquistas das mulheres. Além disso, há um aumento da violência contra a mulher, que caminha com um processo de culpabilização da vítima.

\section{Feminismo, gênero e violências}

No dia que for possível à mulher amar em sua força e não em sua fraqueza, não para fugir de si mesma, mas para se encontrar, não para se renunciar, mas para se afirmar, nesse dia o amor tornar-se-á para ela, como para o homem, fonte de vida e não perigo mortal. (BEAUVOIR, 1980).

A epígrafe acima retrata exatamente o processo de força exercido sobre as mulheres que, ao mesmo tempo, contribuiu com o pensar e lutar dos movimentos sociais feministas, na organização de leis e garantia de direitos às mulheres. Esses movimentos legitimaram-se no decorrer da história e fazem parte de um árduo processo de modificações no campo legal e jurídico.

Ao abordar a temática de políticas públicas de ações afirmativas para as mulheres faz-se necessário contextualizar os movimentos sociais feministas e as questões de gênero. Isso porque, as ações afirmativas para mulheres decorrem de um longo período em que o ser fêmea era sinônimo de fragilidade, devoção ao homem, competência para afazeres domésticos e dom para a maternidade. Estereótipo, esse, que legitimou as violências contra mulheres e as bases cunhadas na opressão, subalternidade e desrespeito ao chamado sexo frágil. Esta desigualdade não é natural e sim construída e absorvida por uma tradição cultural, ratificada por estruturas de poder que tendem a hierarquizar as relações. Há uma supremacia masculina que se incumbiu de socializar a mulher para a docilidade.

[...] as relações de poder suscitam necessariamente, apelam a cada instante, abrem a possibilidade a uma resistência, e é porque há possibilidade de existência e resistência real que o poder daquele que domina tenta se manter com tanto mais força, tanto mais astúcia quanto maior for a resistência. De modo que é mais a luta perpétua e multiforme [...]. (FOUCAULT, 2003, p. 232). 
Contudo, as lutas dos movimentos sociais feministas questionaram esse poder e essa cultura. Tendo em vista que a cultura não é estanque, se modifica através dos tempos, há atualmente uma série de debates acerca dessas violências. Ou seja, muitos costumes antes aceitos, hoje se modificaram, assim a inferiorização e a violência contra as mulheres não são mais culturalmente aceitas. Todavia é preciso compreender que as diferenças entre homens e mulheres ainda pertencem ao reino da natureza biológica. "A prova de que os gêneros masculino e feminino são construções sociais está na própria escola, que já chegou a separar meninos e meninas em salas distintas, contribuindo para fabricar sujeitos diferentes". (MISKOLCI, 2005, p. 14).

As perspectivas em torno do conceito de gênero surgem meados dos anos 1970, debate iniciado por feministas americanas e inglesas, que buscavam explicar a desigualdade existente entre homens e mulheres. A partir da problemática levantada no movimento feminista, as ciências sociais passaram a questionar essa naturalidade supostamente existente entre os sexos (LOURO, 1995, p. 103). De acordo com Guacira Lopes Louro, essa compreensão sobre gênero, leva a pensar como os sujeitos situamse dentro da cultura.

\begin{abstract}
Uma compreensão mais ampla de gênero exige que pensemos não somente que os sujeitos se fazem homem e mulher num processo continuado, dinâmico [...]; como também nos leva a pensar que gênero é mais do que uma identidade aprendida, é uma categoria imersa nas instituições sociais (o que implica admitir que a justiça, a escola, a igreja etc. são "genereficadas", ou seja, expressam as relações sociais de gênero). (LOURO, 1995, p.103).
\end{abstract}

Ao pensar sobre essa compreensão de gênero numa articulação com as relações sociais construídas historicamente, é possível formular a ideia de que os estereótipos e papéis de gênero são produtos de uma situação histórico-cultural e política estruturada em moldes patriarcais, hegemônicos, cristãos e brancos, constatando assim, que não existe naturalmente o gênero masculino ou feminino, mas uma construção cultural de corpos, gêneros e sexualidades. Esses papéis, em geral, privilegiam os homens, como expõe Bourdieu no trecho a seguir.

A dominação masculina encontra assim reunidas todas as condições de seu pleno exercício. A primazia universalmente concedida aos homens se afirma na objetividade de estruturas sociais e de atividades produtivas e reprodutivas, baseadas em uma divisão sexual do trabalho e produção e reprodução biológica e social, que confere ao homem a melhor parte, bem como nos esquemas imanentes a todos os habitus. (BOURDIEU, 2014, p. 54).

Entende-se assim que gênero diz respeito à construção social do que é feminino e do que é masculino (SAFFIOTI, 1999, p. 16) imbricado em relações de poder estruturadas por um padrão do que é certo e do que é errado. Isso significa que "a identidade social da mulher, assim como a do homem, é construída através da atribuição de distintos 
papéis, que a sociedade espera ver cumpridos pelas diferentes categorias de sexo". (SAFFIOTI, 1987, p. 10). Saffioti (1987, p. 08) ressalta que ao compreender os papéis sociais historicamente atribuídos aos sexos é possível refletir sobre o escrito por Simone de Beauvoir: "ninguém nasce mulher, com estereótipos femininos, torna-se mulher, pelo aprendizado cultural".

Em consonância com Del Priore (2013, p. 6), "não importa a forma como as culturas se organizaram”, essa diferença entre homens e mulheres sempre foi hierarquizada. Há registro na história do Brasil, no período colonial, do patriarcalismo que apresentava uma pretensa superioridade masculina em relação às mulheres, que se respaldou em castigos físicos, agressões verbais e assassinatos, autorizados inclusive pela legislação. Essa "desigualdade longe de ser natural, é posta pela tradição cultural, por estruturas de poder e agentes envolvidos na trama de relações sociais”. (SAFFIOTI, 1999, p. 83).

Del Priore esclarece que:

A soma dessa tradição portuguesa com a colonização agrária e
escravista resultou no chamado patriarcalismo brasileiro. Era ele
que garantia a união entre parentes, a obediência dos escravos
e a influência política de um grupo familiar sobre os demais.
Tratava-se de uma grande família reunida em torno de um chefe,
pai e senhor, forte e destemido, que impunha sua lei e ordem
nos domínios que Ihe pertenciam. Sob essa lei, a mulher tinha
de se curvar. (DEL PRIORE, 2013, p. 9-10).

Vale ressaltar que a noção de violência contra as mulheres nem sempre foi compreendida da mesma forma, ou seja, como algo negativo, como um problema social. A violência era naturalmente aceita já que a mulher era considerada um ser inferior, que tinha obrigações, devia obediência e servidão ao homem e ao casamento. Inclusive essa visão era respaldada pelos médicos da época: "por ter ossos, cartilagens, ligamentos e fibra mais frágeis, a mãe apenas carregava o ovo com que o sexo fêmeo concorre para a propagação, assim como sucede com os ovíparos". (DEL PRIORI, 2013. p. 114).

A violência era compreendida como uma espécie de "educação", para disciplinar as mulheres que desrespeitassem os seus homens, sejam eles maridos, pais ou outros. Esse "trabalho de reprodução esteve garantido, até época recente, por três instâncias principais, a família, a igreja e a escola, que, objetivamente orquestradas, tinham em comum o fato de agirem sobre as estruturas inconscientes" (BOURDIEU, 2007, p. 103) e, principalmente, "à família cabe o papel principal na reprodução da dominação e da visão masculina”. (BOURDIEU, 2007, p. 103). Todo esse processo de classificação repercute como um habitus. Compreende-se o conceito de habitus como a relação com as formas de socialização humana, guiadas por meio de dispositivos culturais, repassados de geração para geração, que simulam certa neutralidade e naturalidade das ações cotidianas (BOURDIEU, 1983). "Ora, longe de afirmar que as estruturas de dominação são a-históricas, eu tentarei, pelo contrário, provar que elas são produto de um trabalho incessante (e como tal, histórico) de reprodução [...]". (BOURDIEU, 2014, p. 56). 
A respeito das instituições e dos estereótipos de feminino convém salientar que:

Os pressupostos acerca da inferioridade feminina, presentes no
discurso da Igreja Católica, paradoxalmente, são reafirmados
pelo iluminismo, legitimando-se a exclusão das mulheres da
cidadania política e civil com a Revolução Francesa, apesar do
papel relevante que as mulheres desempenharam no movimento.
Tais teorias ganham força durante o século XIX, adquirindo o
respaldo da ciência, o ídolo do momento. A medicina social
assegura constituírem-se como características femininas, por
razões biológicas, a fragilidade, o recato, o predomínio das
faculdades afetivas sobre as intelectuais, a subordinação da
sexualidade à vocação maternal. (SOIHET, 2002, p. 274).

Em consonância aos estudos da teórica Miriam Grossi (1994, p. 474), a violência como se compreende hoje foi resultado de uma construção história de lutas do movimento feminista que não aceitava mais a justificativa da legítima defesa da honra em favor dos homens que matavam as mulheres. Uma das primeiras manifestações do movimento feminista contra a violência veio com o slogan "Quem ama não mata", em 1979. Na ocasião, o Brasil estava estarrecido com o julgamento de Doca Street, que matou sua companheira Ângela Diniz. Ângela Diniz foi uma socialite brasileira morta a tiros em Búzios em 1976, pelo marido Doca Street que alegou "legítima defesa da honra”, e que, em um primeiro momento, o júri o absolveu. Após pressão da opinião pública e dos movimentos sociais feministas, um novo julgamento o condenou a 15 anos de prisão. Percebe-se, nesse caso, como a violência contra as mulheres estava naturalizada e legalizada.

A sexualidade da mulher sempre foi vigiada e reprimida, não só pela família, mas também a igreja foi uma forte influência nos padrões de comportamento das mulheres (DEL PRIORE, 2013, p. 37). Cabia às mulheres brancas serem trancadas em casa, já as negras “serviam para a fornicação”. (DEL PRIORE, 2013, p. 37).

Até mesmo o matrimônio era escolha do pai para a filha, principalmente se havia bens da família a preservar. Todavia, independentemente de ser uma mulher pobre ou rica, ela tinha um papel estabelecido: cuidar da casa, filhos/as e obedecer ao marido ou ao pai. Para as desobedientes restava o castigo e os maus-tratos, já às que traiam, a morte era o destino. E assim ocorriam "as divisões constitutivas de ordem social e, mais precisamente, as relações sociais de dominação e de exploração são instituídas entre os gêneros [...]". (BOURDIEU, 2007. p. 49).

Mediante às violências cada vez mais em alta, e os crimes contra a vida das mulheres sendo largamente divulgados na mídia, os movimentos sociais a partir da militância do feminismo pressionaram instâncias do Estado a pensarem políticas públicas de atendimento e acolhimento das mulheres, resultando em ações afirmativas em diversos espaços sociais - escola, universidade, trabalho, moradia e bens culturais. Todas as justificativas para o tratamento desigual e do uso de violência contra as mulheres estão hoje em constante desconstrução, constituindo-se base para os movimentos feministas que incorporam em suas pautas a violência doméstica e o direito das mulheres em viver, trabalhar e "circular" socialmente. 
Com o passar dos anos, as desigualdades de gênero começam a ser alteradas e são dispostas relações mais igualitárias. A caminhada dos movimentos feministas obteve transformações sociais, sobretudo no campo dos direitos das mulheres, repercutindo mudanças em todas as dimensões sociais e no entendimento dos papéis a serem desempenhados por homens e mulheres.

Entretanto, apesar das conquistas feministas, ainda perduram assimetrias de gênero, os conflitos originados nas questões relativas às construções de gênero e de identidade, assim como uma visão heteronormativa, incapaz de transcender a esses dualismos. Reforça-se assim, a necessidade de compreensão das políticas de ações afirmativas voltadas para as mulheres.

\section{Ações afirmativas de combate à violência contra as mulheres}

Falar sobre políticas de ações afirmativas é sempre falar de algo polêmico, um campo de direitos individuais, cuja compreensão por parte de alguns, conduz a um entendimento errôneo, voltado a privilégios ofertados para determinados grupos.

As políticas de ações afirmativas são provenientes de reivindicações feitas por movimentos sociais que pressionaram o estado a posicionar-se diante das mazelas sociais. Elas são mecanismos que pretendem por meio da inclusão social, o atendimento prioritário a determinadas pessoas e conferir igualdade de direitos a grupos que tiveram historicamente seus direitos negados, ou seja, nada mais são que políticas públicas sociais que buscam concretizar a igualdade substancial ou material. (GOMES, 2001).

As ações afirmativas constituem em um tipo de um remédio de razoável eficácia para esses males, eliminando ou reduzindo as desigualdades sociais que operam em detrimento das minorias (GOMES, 2001).

Consistem em políticas públicas (e também privadas) voltadas à concretização do princípio constitucional da igualdade material e à neutralização dos efeitos da discriminação racial, de gênero, de idade, de origem nacional, de compleição física e situação socioeconômica (adição nossa). Impostas ou sugeridas pelo Estado, por seus entes vinculados e até mesmo por entidades puramente privadas, elas visam a combater não somente as manifestações flagrantes de discriminação, como também a discriminação de fundo cultural, estrutural, enraizada na sociedade. De cunho pedagógico e não raramente impregnadas de um caráter de exemplaridade, têm como meta, também, o engendramento de transformações culturais e sociais relevantes, inculcando nos atores sociais a utilidade e a necessidade de observância dos princípios do pluralismo e da diversidade nas mais diversas esferas do convívio humano. (GOMES, 2001, p. 6-7).

As mulheres, como grupo social, foram historicamente destituídas de direitos e excluídas por aspectos vinculados ao gênero. Denominadas frequentemente como "sexo frágil", proibidas de gerenciar suas vidas e seus corpos, as mulheres uniram-se por meio de movimentos sociais, a fim de fazer uma interlocução com o estado, buscando 
garantir os seus direitos, demonstrando que as discriminações e desigualdades nas relações de gênero constituem-se dentre várias nuances. (RODRIGUES, 2005).

Vale destacar que, muito "embora se encontre diversos significados em diferentes culturas, as relações de sexo e gênero são, impreterivelmente, correlacionadas aos componentes políticos e econômicos de cada sociedade". (POGGIO, 2012, p. 91).

Assim, a ideia de inferioridade e fragilidade vinculada ao universo feminino funciona como um "selo ou como um carimbo" que validou o preconceito e a violência. O que fez com que a sociedade delimitasse, com bastante precisão, os campos em que a mulher pudesse operar. A socialização dos filhos/as, por exemplo, constituiu em uma tarefa tradicionalmente atribuída as mulheres. (SAFFIOTI, 1987).

Tais relações de subalternidade, discriminação, opressão e violências, fundamentaram a criação de políticas de ações afirmativas para as mulheres.

Compreende-se que "discriminar nada mais é do que uma tentativa de se reduzirem as perspectivas de uns em benefício de outros" (GOMES, 2001, p. 11), ou seja, "quanto mais intensa a discriminação e mais poderosos os mecanismos inerciais que impedem o seu combate, mais ampla se mostra a clivagem entre discriminador e discriminado". (GOMES, 2001, p. 11).

No que tange ao campo penal, gradativamente, leis discriminatórias foram alteradas ou excluídas do ordenamento jurídico, como por exemplo, o crime de adultério, inscrito em todos os códigos penais brasileiros e somente afastado, definitivamente, muito recentemente, pela Lei 11.106, de 2005.

No que diz respeito à Lei do Divórcio, ( $n^{\circ} .6 .515$, de 1977), obteve-se mais um degrau para a igualdade entre homens e mulheres. Essa Lei previu o dever de manutenção dos filhos/as por ambos os cônjuges, na proporção de seus recursos, e abriu nova possibilidade de separação, o que refletiu positivamente para as mulheres em situação de violência. (PIOVESAN, 2009).

Como marco histórico para a construção dos direitos das mulheres, ressalta-se a Constituição Federal de 1988 que demarcou em seu texto vários dispositivos a respeito do princípio da igualdade entre homens e mulheres em todos os campos da vida social (art. $\left.5^{\circ}, \mathrm{l}\right)$, na vida conjugal (art. 226, inciso $5^{\circ}$ ) e, também, a inclusão do art. 226, inciso $8^{\circ}$, em que o Estado se compromete com as questões de violências contra as mulheres. Segundo Alvarez (1988, p.54), “[...] no que tange os direitos das mulheres, a Constituição Brasileira de 1988, pode ser considerada uma das mais progressistas hoje, no mundo".

A esse mesmo período merece total destaque os movimentos de mulheres e feministas, movimentos populares e o Conselho Nacional dos Direitos da Mulher (CNDM) que se organizaram em uma intensa mobilização, com o intuito de defender as mulheres das mais variadas classes, idades e raças, fazendo com que elas fossem ouvidas no Plenário Nacional. 
Com o processo de democratização no país, os movimentos feministas e de mulheres conquistaram uma interlocução o Governo dando início outra fase, a de reconhecimento do Estado de que as discriminações e desigualdades nas relações de gênero constituem umas questões para ser enfrentada por meio da legislação e de políticas públicas. O marco fundamental nesse processo foi à criação do Conselho Nacional dos Direitos da Mulher, em 1985. (RODRIGUES, 2005, p. 30).

Um importante movimento que marcou o movimento feminista ficou conhecido como o Lobby do Batom, ele deu ênfase para que nos anos de 1990 fosse incluída a categoria analítica de gênero e crescesse o debate sobre a cidadania das mulheres em relação ao acesso à direitos e a justiça.

No decorrer dos debates no processo da constituinte, as mulheres se fizeram ouvir e solicitaram os "mesmos direitos e deveres para homens e mulheres na esfera do matrimônio, a inclusão do planejamento familiar, o aperfeiçoamento do conceito de família, a proteção ao trabalho exercido pela mulher etc.". (SENADO FEDERAL, 2004, p.49). "As mulheres brasileiras conseguiram aprovar mais de $80 \%$ de suas demandas, que oscilavam entre o princípio geral da igualdade de gênero e demandas específicas tais como a licença maternidade de quatro meses". (SIMÕES; MATOS, 2010, p.18).

Várias ações começaram a eclodir em todo o mundo sendo fundamental naquele momento, a presença da Organização das Nações Unidas - ONU como um mecanismo importante para estabelecer garantias vitais para as mulheres, contribuindo para a escrita de materiais, pactos e declarações, priorizando as mulheres.

Apresentam-se como importantes documentos: a Declaração Universal de Direitos Humanos (1948), o Pacto internacional de Direitos Civis e Políticos (1966), o Pacto internacional dos Direitos econômicos, sociais e culturais (1966); ambos abordam a igualdades de direitos entre os sexos, mas não são documentos diretamente dirigidos para mulheres, mesmo que as incorpore nos seus artigos; a Convenção sobre a Eliminação de todas as Formas de Discriminação contra as Mulheres de 1979; a Convenção Interamericana para prevenir, punir e erradicar a violência contra a mulher assinada em 1994 e o Compromisso de Dakar (2000) realizado junto ao Fórum Mundial de Educação referente à universalização da educação e a igualdade entre os gêneros, buscando eliminar as "disparidades existentes entre os gêneros na educação primária e secundária e, até 2015, atingir a igualdade entre os gêneros em educação". (UNESCO, 2001, p. 20).

Quanto a um documento diretamente direcionado para mulheres, pode-se citar a Convenção para a Eliminação de todas as formas de discriminação contra a mulher (1979 - ONU) e a Convenção Interamericana para Prevenir, Punir e Erradicar a Violência Contra a Mulher (Convenção de Belém do Pará, 1994 - Organização dos Estados Americanos - OEA) (PIOVESAN, 2009).

Dentre os aparatos de luta dos movimentos feministas é importante atentar para algumas datas históricas (Quadro 1) para os direitos das mulheres. 
Quadro I: diretos das mulheres ao longo da história

\begin{tabular}{|c|c|}
\hline \multicolumn{2}{|c|}{ Direitos da Mulher } \\
\hline 1915 & $\begin{array}{l}\text { - Foi instituído um novo regulamento para a Caixa Econômica Federal que, dentre } \\
\text { outras alterações no seu funcionamento, permitia que a mulher casada possuísse } \\
\text { depósitos bancários em seu nome quando não houvesse oposição do marido. }\end{array}$ \\
\hline 1916 & - Até 1916 o marido tinha o direito de aplicar castigos na sua mulher. \\
\hline 1932 & - As mulheres receberam o direito ao voto. \\
\hline 1945 & $\begin{array}{l}\text { - A igualdade de direitos entre homens e mulheres é reconhecida em documento } \\
\text { internacional, através da Carta das Nações Unidas. }\end{array}$ \\
\hline 1962 & $\begin{array}{l}\text { - É criado o Estatuto da Mulher casada, que garantiu entre outras coisas que } \\
\text { a mulher não precisava mais de autorização do marido para trabalhar, receber } \\
\text { herança e em caso de separação ela poderia requerer a guarda dos filhos. }\end{array}$ \\
\hline 1980 & $\begin{array}{l}\text { - Recomendada a criação de centros de autodefesa, para coibir a violência } \\
\text { doméstica contra a mulher. Surge o lema: Quem ama não mata. }\end{array}$ \\
\hline 1985 & - Foi criado o Conselho Nacional dos Direitos da Mulher (CNDM). \\
\hline 1988 & - Foi consagrada a igualdade jurídica entre homens e mulheres. \\
\hline 2002 & - O termo "patrio poder" foi substituído pelo "poder familiar". \\
\hline 2006 & - Foi promulgada a Lei Maria da Penha. \\
\hline 2015 & - Promulgada a Lei do Feminicídio. \\
\hline
\end{tabular}

Fonte: Elaboração própria a partir de vários materiais.

A partir de 1990, várias outras formas de violência contra as mulheres começam a ser problematizadas, aceitas e visibilizadas, tais como: a destruição de objetos pessoais, a humilhação e tensão conjugal, a violência física e simbólica durante a gravidez, práticas discriminatórias no trabalho, preconceitos e violências contra grupos específicos de mulheres, como negras e indígenas. (GROSSI, 1994, p. 475).

Saffioti (1999) afirma que a violência contra as mulheres é uma expressão do patriarcado e incorpora a violência familiar, intrafamiliar (vai além dos limites do domicílio) e a violência doméstica (atinge pessoas que moram no mesmo espaço).

Sobre o conceito de violência de gênero, esse é mais amplo, pois abrange dentre as vítimas, mulheres, crianças e adolescentes de ambos os sexos. (SAFFIOTI, 1999). $A$ violência contra as mulheres em razão do gênero deve ser relacionada com os demais marcadores de desigualdade social, compreendendo, assim, as intersecções como fatores que agregam as violências. É essencial atentar as interseccionalidades em relação às violências, pois as mulheres negras são duplamente violentadas, em virtude da cor e do sexo. Perceber as singularidades de cada violência é perceber que os marcadores sociais são mais desiguais em relação à raça, etnia, classe, orientação sexual, idade e identidade de gênero.

Sobre a violência simbólica, pode-se compreender que ela se revela como um espaço ao qual "se manifestam relações de poder, o que implica afirmar que ela 
se estrutura a partir da distribuição desigual de um quantum social que determina a posição que um agente específico ocupa em seu seio". (BOURDIEU, 1983, p. 21).

Miriam Abramovay et al. (2002, p. 335) retrata que é importante perceber as diversas manifestações da violência simbólica embasadas no abuso do poder e fundamentadas no que ou em quem se vê como autoridade. Já para Roger Chartier (1995) falar de violência simbólica é "compreender como a relação de dominação, em seus aspectos históricos, culturais e linguísticos, é sempre afirmada como uma diferença de natureza, radical, irredutível, universal”. (CHARTIER, 1995, p. 42).

Cabe aqui esclarecer que as ações afirmativas para as mulheres não são apenas para a eliminação das violências, há outras leis que fazem parte da luta por políticas públicas de direito, tais como:

- Lei n. ${ }^{\circ}$ 9.100, de 1995, que determinou uma reserva mínima de 20\% das vagas dos partidos políticos ou coligações para serem preenchidas por mulheres candidatas.

- Lei n. ${ }^{\circ}$ 9.029, de 1995, proíbe qualquer prática discriminatória ou limitante com relação ao emprego.

- Lei n. $\quad$ 8.213, de 1991, estabelece o pagamento, pela empresa, do salário maternidade.

Mesmo considerando a importância dessas leis, não há como fazer um comparativo delas em relação às leis de proteção à vida das mulheres tais como: as delegacias especiais, a Lei Maria da Penha ( $n^{\circ} 11.340$, de 2006) e os canais de atendimentos.

Nesse sentido, apresentam-se na Tabela 1 alguns dados estatísticos em relação a essas violências, já que o Brasil está na sétima posição mundial, chegando ao número de onze mortes de mulheres por dia (BRASIL, 2013, p. 103).

Tabela 1: Tipos de Violências Sofridas pelas Mulheres no Brasil

\begin{tabular}{lcc}
\hline Tipo de Violência & Total & Percentual \\
\hline Total & 88.668 & 100 \\
\hline Violência física & 50.236 & 56,6 \\
Violência psicológica & 24.478 & 27,6 \\
Violência moral & 10.372 & 11,7 \\
Violência sexual & 1.686 & 1,9 \\
Violência patrimonial & 1.426 & 1,6 \\
Cárcere privado & 430 & 0,4 \\
Tráfico internacional de pessoas & 21 & 0,1 \\
Tráfico interno de pessoas & 19 & 0,1 \\
\hline
\end{tabular}

Fonte: Central de atendimento à mulher - Brasília-DF, 2012 (Brasil, 2013) - Elaboração própria. 
Destaca-se o caso das violências psicológicas e morais que se configuram como violência simbólica. Os dois tipos de violências somam 39,3\%, um índice bem elevado e que merece atenção. Em geral, essas violências não são entendidas como tais, pois se tornam naturalizadas nas práticas cotidianas. Pesquisas mostram que a violência psicológica e moral (simbólicas) são praticadas por pessoas próximas as mulheres, como maridos, namorados, companheiros, chefes ou parentes, e se apresentam, de certo modo, como "brincadeiras" que não devem ser levadas a sério, nem sequer denunciadas, conforme salienta Saffioti (2015), há uma naturalização da violência enquanto um destino traçado para as mulheres.

As violências física, sexual, emocional e moral não ocorrem isoladamente. Qualquer que seja a forma assumida pela agressão, a violência emocional está sempre presente. Certamente, se pode afirmar o mesmo da moral. O que se mostra de difícil utilização é o conceito de violência como uma ruptura de diferentes tipos de integridade: física, sexual, emocional, moral, Sobretudo em se tratando de violência de gênero, e mais especificamente intrafamiliar e doméstica, são muito tênues os limites entre quebra de integridade e obrigação de suportar o destino de gênero traçado para mulheres: sujeição aos homens, sejam pais ou maridos. (SAFFIOTI, 2015, p. 79-80).

Percebe-se que as violências não ocorrem de forma isolada, mesmo porque há um certo "ritual" nas formas de fazer acontecer cada ato. Eles podem iniciar com cerceamentos de vontades e desejos, como comprar uma roupa, cortar o cabelo, conversar com as amigas, chegando a atos físicos. Algumas vezes os atos físicos não ocorrem, mas a carga emocional decorrente das violências psicológicas pode ser maior que qualquer agressão. "Desta maneira, cada mulher colocará o limite em um ponto distinto do continuum entre a agressão e o direito dos homens sobre as mulheres. Mais do que isto, a mera existência desta tenuidade representa violência". (SAFFIOTI, 2015, p. 80).

Tabela 2: Tipos de Violências Psicológicas

\begin{tabular}{lcc}
\hline Violência Psicológica & Total & Percentual \\
\hline Total & 24.478 & 100 \\
\hline Ameaça & 11.630 & 47,5 \\
Dano emocional/diminuição da autoestima & 10.353 & 42,3 \\
Outros & 1.264 & 5,2 \\
Perseguições & 1.147 & 4,7 \\
Assédio moral & 84 & 0,3 \\
\hline
\end{tabular}

Fonte: Central de atendimento à mulher - Brasília-DF, 2012 (Brasil, 2013) - Elaboração própria. 
Na tabela 2 estão discriminados os tipos de violências psicológicas que as mulheres relataram por meio das ligações para a Central de atendimento à mulher. Essa Central foi criada em 2005, e se tornou um importante instrumento de denúncia, por ter como objetivo ajudar as mulheres em situação de violência, informando-as sobre os seus direitos e sobre os serviços disponíveis para atendê-las. De acordo com

\begin{abstract}
A análise dos registros de violência psicológica segundo o tipo evidencia uma clara predominância de ameaças $(47,5 \%)$ e de danos emocionais, além da diminuição da autoestima (42,3\%). As perseguições somam $5 \%$ do total dos registros de violência psicológica, o patamar mais estruturado e organizado da prática desse tipo de violência. O assédio moral, como modalidade de violência psicológica, foi relativamente pouco mencionado nos registros da Central. Uma possível explicação para essa baixa notificação é o fato de que muitos casos de assédio moral são classificados como pedido de informações pelas atendentes da Central, o que dificulta dimensionar mais precisamente o fenômeno. (BRASIL, 2013, p. 106).
\end{abstract}

É necessário analisar as informações contidas nas tabelas, como indicadores que apontam a situação das mulheres na nossa sociedade, buscando assim, ampliar as políticas públicas para o atendimento das mulheres em situação de violência, já que "a supremacia masculina nas esferas públicas e privadas se traduz em consenso e muitas vezes se estabelece por meio da violência”. (POGGIO, 2012, p. 90).

Quando analisamos os dados a partir de uma visão de gênero, verificamos que a distribuição dos homicídios não é equitativa, nem igualitária. Acompanha bem de perto nossas mazelas sociais. Por esse motivo, é um indicador privilegiado dos conflitos e mecanismos de segregação social que os discursos (público e privado) tendem a ocultar. Os estudos existentes demonstram coincidentemente que a vitimização homicida no país é notada e fundamentalmente masculina. A feminina representa aproximadamente $8 \%$ do total de homicídios, mas com características bem diferenciadas da mortalidade masculina. (BRASIL, 2013, p. 105).

Ressalta-se aqui, novamente, a interseccionalidade existente nas violências, em relação a questão da cor juntamente com o gênero. As mulheres negras somam $60 \%$ dos assassinatos entre 2001 e 2011, de acordo com o Instituto de Pesquisa Econômica Aplicada - IPEA (BRASIL, 2013).

Sobre a Lei Maria da Penha (Lei 11340/06 I Lei n 11.340, de 7 de agosto de 2006), ela deve ser subsidiada por delegacias de atendimento e proteção às mulheres vítimas de violência, entretanto não são todas as regiões do Brasil que as possuem, todavia, na falta delas, o atendimento deve ser priorizado nas demais delegacias, porém, os profissionais não são treinados para esse tipo de atendimento. 
A Lei Maria da Penha atua para a redução das desigualdades de gênero, isso porque, as questões das violências estão imbricadas nas "relações de gênero se instituem de modo hierárquico e pressupõe em última análise, relações de dominação e submissão" (POGGIO, 2012, p. 90), "a força da ordem masculina se evidencia no fato de que ela dispensa justificação: a visão androcêntrica impõe-se como neutra e não tem necessidade de se anunciar em discursos que visem legitimá-la". (BOURDIEU, 2007, p. 22).

Durante um longo período no Brasil a legítima defesa da honra era um argumento utilizado por juristas para absolver os acusados de matar mulheres. Desse modo, a criação de ações afirmativas específicas para as mulheres, incluindo as leis de proteção e atendimento, as delegacias especiais para atender as vítimas, agregam um fortalecimento nas relações de gênero.

Muitos obstáculos foram rompidos, principalmente após a criação da Lei Maria da Penha, por conseguinte, lutar contra as desigualdades, obter mudanças nos hábitos e comportamentos misóginos ainda está na pauta dos movimentos feministas.

\section{Considerações Finais}

Muito mais que apenas debater uma questão de gênero, o artigo apresenta elementos para compreensão do feminismo, das violências institucionalizadas contra as mulheres e sobre a necessidade das ações afirmativas adotadas ao longo dos tempos.

Dentro de vários aspectos problematizados, buscou-se enfatizar como o movimento feminista contribuiu para pensar a relação das mulheres com a desigualdade, as relações de poder e a determinação biológica culturalmente naturalizada. O importante aqui foi, sobretudo, identificar os mecanismos que enunciam e representam como "naturais" as violências cometidas contra as mulheres. (CHARTIER, 1995).

O movimento feminista efetuou mudanças na sociedade ocidental, iniciando pelo sufrágio feminino, o acesso à educação, salários mais equitativos com os dos homens, o direito de iniciar o processo de divórcio, o direito da mulher de tomar decisões individuais relativas à gravidez (acesso aos contraceptivos) e até mesmo o direito de propriedade privada.

Entretanto, as representações culturais disseminadas ao logo da história enraizaram e naturalizaram a violência contra mulher. Interiorizada em uma cultura predominantemente machista, essa violência ainda possui índices muito elevados.

As ações afirmativas para combater a violência contra as mulheres originam-se do reconhecimento das violações vivenciadas pelo gênero feminino que historicamente foi posto em situação de desvantagem e de discriminação.

Assim, mais do que uma questão de gênero, é preciso demonstrar como os discursos misóginos, machistas e sexistas estão articulados a uma ideologia cultural que reforça a superioridade do macho sobre a fêmea, sustentando desde a infância um alinhamento dos corpos a estereótipos daquilo que se configura como feminino e do que é ser masculino. 
A cultura, por intermédio das mídias, da família ou da literatura, impregna de todos os lados uma representação de felicidade relacionada ao casamento, à maternidade ou ao lar. A mulher acaba sendo sempre a que cuida e a que está relacionada com a docilidade, como se isso foi intrínseco de cada uma.

Vale lembrar que o mundo machista também faz mal aos homens, que são cobrados para serem viris, durões, não chorar e não terem fraquezas. Isso fez com que se tornassem cada vez mais agressivos e não admitissem que a mulher lhe fosse superior, a cultura patriarcal acarretou em violências para ambos os gêneros, todavia, para as mulheres, isso resultou em perdas nos processos de escolarização e empregabilidade.

Por fim, ressalta-se que esse debate permite compreender que as violências contra as mulheres são violações de direitos humanos e, por isso, atingem todas as classes sociais. A igualdade de direitos é alvo de lutas realizadas ao longo dos séculos, sendo ainda hoje uma das principais preocupações de grupos dos movimentos sociais feministas.

\section{Referências}

ABRAMOVAY, Miriam et al. Escola e violência. Brasília: UNESCO, 2002.

ALVAREZ, Sonia E. Politizando as relações de gênero e engendrando a democracia. In: STEPAN, Alfred. (Org.). Democratizando o Brasil. Rio de Janeiro: Paz e Terra, 1988, p. 324-326.

AZEVEDO, J. M. L. de. A educação como política pública. Campinas: Autores Associados, 2004.

BEAUVOIR, Simone de. O segundo sexo: fatos e mitos. 2. ed. v. 1 Tradução: Sérgio Millet. Rio de Janeiro: Nova Fronteira, 1980.

BOURDIEU, Pierre. Sociologia. São Paulo: Ática, 1983.

BOURDIEU, Pierre. A dominação masculina. 5. ed. Rio de Janeiro: Bertrand Brasil, 2007.

BOURDIEU, Pierre. A dominação masculina. Trad. Maria Helena Kühner 2. Ed. Rio de Janeiro: Edições Best Bolso, 2014.

BRASIL. Presidência da República. Secretaria de Políticas para as Mulheres. Relatório Anual Socioeconômico das Mulheres. 1. Impr. Brasília: Secretaria de Políticas para as Mulheres, 2013.

CHARTIER, Roger. Diferença entre os sexos e dominação simbólica (nota crítica). In: Cadernos Pagu. (4), 1995.

DEL PRIORE, Mary. Histórias e Conversas de Mulher. São Paulo: Planeta, 2013. 
FOUCAULT, Michel. Sexualidade e Poder. Em Ética, Sexualidade, Política: Coleção Ditos \& Escritos. Rio de Janeiro: Forense Universitária, 2003.

GOMES, Joaquim Benedito Barbosa. Ação Afirmativa e Princípio Constitucional da Igualdade: o direito como instrumento de transformação social. A experiência dos EUA. Rio de Janeiro: Renovar, 2001.

GROSSI, Miriam Pillar. Novas/Velhas Violências contra a Mulher no Brasil. Revista Estudos Feministas - REF. Ano 2, $2^{\circ}$ sem., 1994, p. 473-483.

HÖFLING, E. de M. Estado e políticas (públicas) sociais. In: Cadernos Cedes, ano XXI, n. 55, nov. 2001. Disponível em: <http://scielo.br/pdf/ccedes/v21n55/5539>. Acesso em: 10 jan. 2015.

LANZ, Letícia. O corpo da roupa: a pessoa transgênera entre a transgressão e a conformidade com as normas de gênero. Dissertação, mestrado em Sociologia. Universidade Federal do Paraná. Curitiba, 2014.

LOURO, Guacira Lopes. Gênero, história e educação. Educação \& Realidade, Porto Alegre, v. 20, n.2, jul. /dez.1995.

MISKOLCl, Richard. Um Corpo Estranho na Sala de Aula. In: Abramowicz, Anete; Silvério, Valter Roberto (Org.). Afirmando Diferenças: Montando o Quebra Cabeça da Diversidade da Escola. Campinas: Papirus, 1ed., v. 1, 2005. P. 13-26.

PIOVESAN, Flávia. Direitos Humanos e o Direito Constitucional. 10 ed. Rev. Atual. São Paulo: Saraiva, 2009.

POGGIO, Inês Soares Nunes. A construção das relações de gênero. In: LAFFIN, Maria Hermínia Lage Fernandes (Org.). Educação de jovens e adultos, diversidade e o mundo do trabalho. ljuí: Ed. Unijuí, 2012. p. 88-101.

RODRIGUES, Almira. Lugar de mulher é na política: um desafio para o século XIX. In: SWAIN, Tania Navarro e MUNIZ, Diva do Couto Gontijo. (Org.). Mulheres em ação: práticas discursivas, práticas políticas. Florianópolis: Ed. Mulheres; Belo Horizonte: PUC Minas, 2005.

SAFFIOTI, Heleieth. O poder do macho. São Paulo: Moderna, 1987.

SAFFIOTI, Heleieth. Gênero patriarcado violência. 2a ed. São Paulo: Expressão Popular: Fundação Perseu Abramo, 2015.

SAFFIOTI, Heleieth. Já se mete a colher em briga de marido e mulher. São Paulo em Perspectiva 13 (4) p. 82-91, 1999. Disponível em: <http://www.scielo.br/scielo. php?script=sci_arttext\&pid=SO>.

SANTANA, Anabela Maurício de. Fragmentações e permanências: gênero e diversidade na escola. Retratos da Escola, Brasília, jan. 2015. p.123-136. 
SENADO FEDERAL (Org.). Comissão temporária do ano da mulher: senado federal subsecretaria de arquivo, 2004.

SIMÕES, Solange e MATOS, Marlise. Ideias Modernas e Comportamentos Tradicionais: a persistência das desigualdades de gênero no Brasil. In: SOUZA, Márcio Ferreira de. (Org.). Desigualdades de gênero no Brasil: novas ideias e práticas antigas. Belo Horizonte: Argvmentvm, 2010.

SOIHET, Rachel. O corpo feminino como lugar de violência. In: Projeto História, $\mathrm{n}^{\circ} 25$, São Paulo: EDUC, dez. de 2002.

UNESCO - Organização das Nações Unidas para a Educação, a Ciência e a Cultura. Educação para Todos: o compromisso de Dakar. Brasília: UNESCO, CONSED, Ação Educativa, 2001. 70 p. Disponível em: <http://unesdoc.unesco.org/ images/0012/001275/127509porb.pdf>. Acesso em 17 out. 2017.

Samira de Moraes Maia VIGANO é Doutora em Educação e Professora no Instituto Federal de Educação Ciência e Tecnologia de Santa Catarina e Orientadora Pedagógica na Universidade Federal de Santa Catarina.

Maria Hermínia Lage Fernandes LAFFIN é Doutora em Educação pela Universidade Federal de Santa Catarina e Professora do Programa de Pós-Graduação em Educação da mesma Universidade. Coordena o Grupo de Pesquisa em Educação de Jovens e Adultos (EPEJA). 